\title{
Intrathrombotic appearances of AQP-1 and AQP-3 in relation to thrombus age in murine deep vein thrombosis model
}

\author{
Mizuho Nosaka ${ }^{1} \cdot$ Yuko Ishida $^{1}$ - Yumi Kuninaka ${ }^{1}$ - Akiko Ishigami ${ }^{1} \cdot$ Akira Taruya $^{2} \cdot$ Emi Shimada $^{1}$. \\ Yumiko Hashizume ${ }^{1} \cdot$ Hiroki Yamamoto ${ }^{1}$ - Akihiko Kimura ${ }^{1}$ • Fukumi Furukawa ${ }^{1,3}$ • Toshikazu Kondo ${ }^{1}$ (D)
}

Received: 25 August 2020 / Accepted: 9 December 2020 / Published online: 7 January 2021

(C) The Author(s), under exclusive licence to Springer-Verlag GmbH, DE part of Springer Nature 2021

\begin{abstract}
Aquaporins (AQPs) are membrane-bound proteins for water transportation and are useful for diagnosing drowning and wound vitality in forensic pathology. Here, we examined intrathrombotic expression of AQP-1 and AQP-3 using deep vein thrombosis models in mice. To perform immunohistochemical analyses, we used anti-AQP-1 and anti-AQP-3 antibodies. In thrombus samples with the post-ligation intervals of 1 to 5 days, AQP- $1^{+}$areas were over $70 \%$. At 7 days after the IVC ligation, AQP$1^{+}$areas became less than $50 \%$, eventually decreasing to $11 \%$ at 21 days. At 3 days after the IVC ligation, AQP- $3^{+}$cells started to appear from the peripheral area. Thereafter, the positive cell number progressively increased and reached to a peak at 10 days after the IVC ligation. When the intrathrombotic AQP-1 $1^{+}$area was as large as the intrathrombotic collagen area or smaller, it would indicate a thrombus age of $\geq 10$ days. AQP- $3^{+}$cell number of $>30$ would indicate a thrombus age of 10-14 days. Collectively, our study implied that the detection of AQP-1 and AQP-3 would be useful for the determination of thrombus age.
\end{abstract}

Keywords Forensic pathology $\cdot$ Thrombus age determination $\cdot$ Immunohistochemistry $\cdot$ Aquaporin $1 \cdot$ Aquaporin 3

\section{Introduction}

The movement of water into and out of cells is a fundamental biological process that keeps the water volume of human body at approximately $70 \%$. Aquaporins (AQPs) are membrane-bound channel proteins distributed in most tissues for the water transport, and there are currently 13 AQPs in mammals [1-3]. AQPs are involved in the physiological processes such as regulation in the ovine fetal lung liquid, urinary concentration, body fluid homeostasis, brain function, glandular secretion, skin hydration, male fertility, hearing, and vision [3, 4]. Moreover, AQPs are also associated with several pathological disorders such as cancer progression, angiogenesis, Parkinson's disease, and disc herniation [5-8].

From the forensic aspects, pulmonary thromboembolism resulting from deep vein thrombosis (DVT) is one of the

Toshikazu Kondo

kondot@wakayama-med.ac.jp

1 Department of Forensic Medicine, Wakayama Medical University, 811-1 Kimiidera, Wakayama 641-8509, Japan

2 Department of Cardiovascular Medicine, Wakayama Medical University, 811-1 Kimiidera, Wakayama 641-8509, Japan

3 Takatsuki Red Cross Hospital , 1-1-1 Abuno, Takatsuki, Osaka 569-1096, Japan major causes that occurs sudden unexpected death. We explored the pathophysiology of DVT from the viewpoints of both forensic and molecular pathology $[9,10]$. Subsequently, we found key roles of several cytokines such as IFN- $\gamma$, TNF- $\alpha$, and IL- 6 in the resolution of DVT using knockout mice [11-13]. It is one of the important matters to determine how long before a wound has been sustained or a thrombus has been formed [14-20]. Thus, we reported several specific cell and markers for the estimation of thrombus age $[9,10]$.

Previously, we demonstrated the forensic significances of AQP-1 and AQP-3 from the determination of wound vitality or ages $[21,22]$. In the present study, we immunohistochemically examined intrathrombotic appearance of AQP-1 and AQP-3 and discussed the possibility of their application to thrombus age estimation in forensic practices.

\section{Materials and methods}

\section{Stasis-induced deep vein thrombus model}

Specific pathogen-free 8- to 10-week-old male BALB/c mice were purchased from SLC (Shizuoka, Japan). Intravenous thrombus was induced as described previously [10-13]. 
Under the deep anesthesia, an incision was made on the abdominal wall, and the inferior vena cava (IVC) was exposed and ligated. At the indicated time intervals, mice were euthanized by the inhalation of over-dose isoflurane, and thrombus samples were obtained. At each time point, 5 mice were used. All animal experiments were approved by the Committee on Animal Care and Use of the Wakayama Medical University.

\section{Histopathological analyses and immunohistochemistry}

Thrombus samples were fixed in $4 \%$ formaldehyde buffered with PBS (pH 7.2), and 4- $\mu$ m-thick paraffin-embedded sections were made [10]. For histopathological analyses, deparaffinized sections were stained with Masson's trichrome (MT) staining [11-13, 23]. As described previously, immunostaining of AQP-1, AQP-3, and F4/80 was performed by Ventana Discovery® XT (Ventana Medical Systems, Inc., AZ, USA) using rabbit anti-AQP-1 polyclonal antibodies (pAbs) (sc-20810, $2 \mu \mathrm{g} / \mathrm{ml}$; Santa Cruz Biotechnology, Inc., Santa Cruz, CA, USA), goat anti-AQP-3 pAbs (sc-9885, $2 \mu \mathrm{g} / \mathrm{ml}$; Santa Cruz Biotechnology, Inc., Santa Cruz, CA, USA), and rat anti-F4/80 monoclonal $\mathrm{Ab}(40 \mu \mathrm{g} / \mathrm{ml}$; Serotec, Oxford, UK) $[10,11,13]$.

\section{Double-color immunofluorescence analysis}

Double-color immunofluorescence analysis of AQP-3 and F4/80 was performed by Ventana Discovery® XT [13]. Deparaffinized sections were incubated in a combination of rabbit anti-AQP-3 pAbs and rat anti-F4/80 mAb. After incubation with FITClabeled ( $3 \mu \mathrm{g} / \mathrm{ml}$; Jackson ImmunoResearch Laboratories, West Grove, PA) and Cy3-labeled secondary pAbs $(0.75 \mu \mathrm{g} / \mathrm{ml}$; Jackson ImmunoResearch Laboratories), the sections were observed by fluorescence microscopy $[15,17]$.

\section{Morphometrical analysis of $\mathrm{AQP}-1^{+}$area and collagen deposition}

Intrathrombotic collagen deposition was semi-quantitated as the blue area in MT-stained sections [23]. AQP- $1^{+}$brown area in the thrombus was evaluated by ImageJ analysis software Ver. 1.50a (National Institute of Health, USA) and expressed as the percentage of the whole thrombus area [24].

\section{Semi-quantitative evaluation}

Intrathrombotic $\mathrm{AQP}-3^{+}$cells and $\mathrm{F} 4 / 80^{+}$cells were evaluated semi-quantitatively, as described previously $[10,11,25]$. Immunopositive cells were enumerated in five high-power fields (hpf; $\times 1000)$ within the thrombus; the total numbers in the five fields were combined. All measurements were performed by two examiners without prior knowledge.

\section{Statistical analysis}

All data are presented as the mean \pm SEM. To compare the values between two groups, Student's $t$ test or Welch $t$ test was performed. All statistical analyses were performed using Statcel4 software.

\section{Results}

\section{Intrathrombotic appearance of $\mathrm{AQP}-1^{+}$area and collagen content area}

In the thrombus samples with the post-ligation intervals of 1 to 7 days, numerous AQP- $1^{+}$erythrocytes were found. Thereafter, $\mathrm{AQP}-1^{+}$erythrocyte areas were gradually decreased in accordance with the thrombus ages. However, AQP- $1^{+}$erythrocyte was still detected in 21-day-old thrombus samples (Fig. 1a). In mirror to these observations, MT-stained blue area was hardly found in the early time points after IVC ligation, and the blue area was increased in the thrombus sample aged 7 days or more (Fig. 1b). We performed the semi-quantitation assay to obtain the $\mathrm{AQP}-1^{+}$area and MT-stained blue area to the thrombus formation area on the cross section of the thrombi. In thrombus samples with the post-ligation intervals of 1 to 5 days, $\mathrm{AQP}-1^{+}$areas and MT-stained blue area were over $70 \%$ and $<10 \%$, respectively. At 7 days after the IVC ligation, AQP- $1^{+}$areas became less than $50 \%$, eventually decreasing to $11 \%$ at 21 days (Table 1 , Fig. 1c). On the contrary, MT-stained blue area started to increase from the peripheral area of the thrombi at day 7 or more, reaching to $>80 \%$ at day 21 (Table 1, Fig. 1c). In thrombus samples aged less than 7 days, AQP-1 $1^{+}$area was dominant to MT-stained blue area (Fig. 1c). Moreover, AQP-1-positive signals were detected in the endothelial cells of neovessels later than 10 days after the IVC ligation (Fig. 2a), and the number of AQP-1-positive neovessels increased time dependently (Fig. 2b).

\section{Intrathrombotic distributions of $\mathrm{AQP}-3^{+}$cell and macrophages}

In 1-day-old thrombus samples, $\mathrm{AQP}-3^{+}$cells could not be detected in thrombi. At 3 days after the IVC ligation, AQP$3^{+}$cells started to appear from the peripheral area. Thereafter, the positive cell number progressively increased and reached to a peak at 10 days after the IVC ligation (Fig. 3). Moreover, we found that AQP-3 was colocalized in $\mathrm{F} 4 / 80^{+}$macrophages (Fig. 4a). Although there was no thrombus sample with the $\mathrm{AQP}-3^{+}$cell number of $>30$ in the post-ligation intervals of $\leq$ 7 days, all of thrombus samples aged 10 and 14 days had the AQP- $3^{+}$cell number of $>30$ (Table 2, Fig. 3b). Calculating the ratio of $\mathrm{AQP}-3^{+}$macrophage number to total macrophage number, almost of thrombus samples aged $\leq 7$ days had the ratio of $<50 \%$. 
Table 1 Mean intrathrombotic $\mathrm{AQP}-1^{+}$area and collagen content area in each thrombus age group $(n=4-5)$

\begin{tabular}{llcc}
\hline $\begin{array}{l}\text { Thrombus age } \\
\text { day) }\end{array}$ & $\begin{array}{l}\% \text { AQP-1 } \\
\text { Mean } \pm \text { SEM (range) }\end{array}$ & $\begin{array}{l}\text { \% collagen content area } \\
\text { Mean } \pm \text { SEM (range) }\end{array}$ & \begin{tabular}{l}
$\begin{array}{l}\text { Intrathrombotic neovessels/ } \\
\mathrm{mm}^{2} \\
\text { Mean } \pm \text { SEM (range) }\end{array}$ \\
\hline 1
\end{tabular} \\
3 & $92.72 \pm 3.29(83.32-99.14)$ & $0.64 \pm 0.37(0.17-2.09)$ & $0(-)$ \\
5 & $76.96 \pm 3.09(67.51-86.89)$ & $0.92 \pm 0.40(0.11-1.97)$ & $0(-)$ \\
7 & $70.02 \pm 4.19(57.29-79.73)$ & $5.51 \pm 0.29(4.52-6.32)$ & $1.42 \pm 0.57(0-3.18)$ \\
10 & $45.96 \pm 6.04(29.46-63.96)$ & $22.07 \pm 2.11(16.91-29.37)$ & $3.05 \pm 0.50(1.86-4.41)$ \\
14 & $40.71 \pm 4.77(27.00-51.89)$ & $42.70 \pm 5.06(24.88-52.84)$ & $6.02 \pm 0.95(3.96-8.99)$ \\
21 & $22.43 \pm 5.62(9.82-32.04)$ & $57.94 \pm 8.55(25.11-72.60)$ & $21.20 \pm 2.52(14.47-25.67)$ \\
\hline
\end{tabular}

\section{Discussion}

It is needless to say that forensic medicine is not just basic but applied medicine that diagnoses the cause of death, the mechanism of wounding, and wound ages. Thus, in order to improve the accuracy and objectivity of diagnosis, advanced scientific and medical knowledges and information should be applied to forensic practices. AQPs are indispensable molecule for water movement in mammals, which prompted us to explore the relationship between drowning and AQP expression. In 2009, our research group firstly examined intrapulmonary AQP5 expression from the aspects of differentiation between freshwater and saltwater drowning
[26]. Thereafter, there are several studies on the AQP-associated forensic practices such as brain edema, pulmonary edema, and hyper- or hypothermia [27-29].

It is well known that there are similar points such as inflammatory cell migration, neovascularization, and collagen accumulation in pathophysiology between skin wound healing and thrombus formation/resolution. Thus, we found several common markers for the determination of both wound ages and thrombus ages. In addition to the differentiation between freshwater and saltwater drowning [30,31], we demonstrated the usefulness of AQP-1 and AQP-3 in the determination wound vitality or ages $[21,22]$. These observations implied a

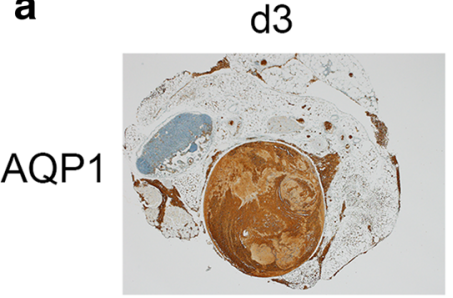

b

MT

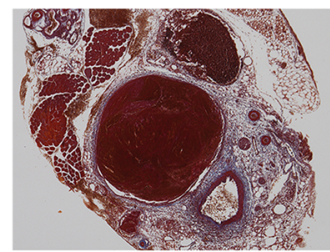

d7
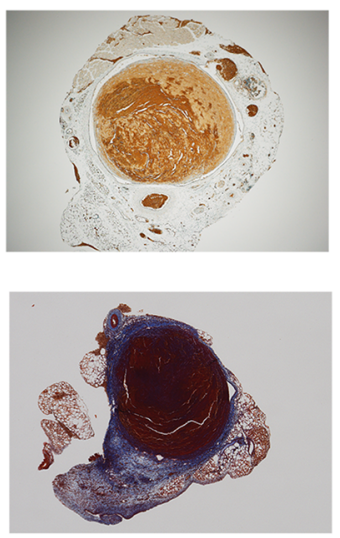

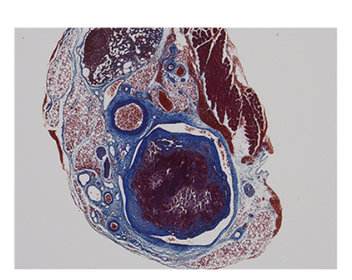

d14

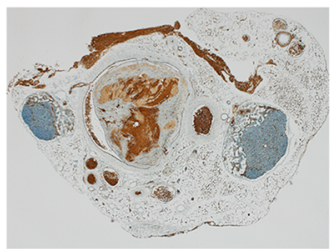

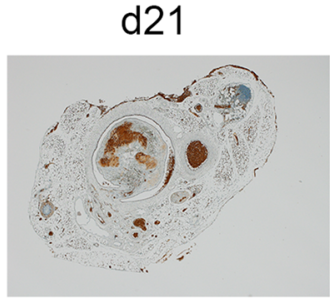

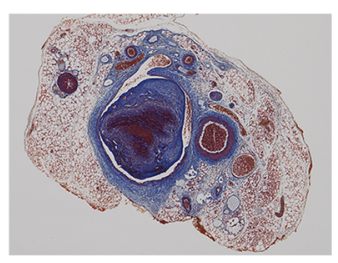

$1 \mathrm{~mm}$

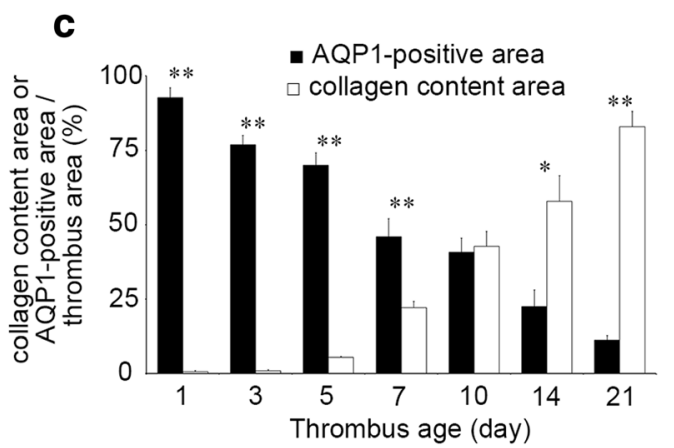

Fig. 1 (a) Immunohistochemical detection of murine intrathrombotic AQP-1 and (b) Masson's trichrome staining images of murine thrombi at 3, 7, 14, and 21 days after IVC ligation. Original magnification: $\times 100$. (c) Relationship of intrathrombotic AQP- $1^{+}$area and collagen + area 
Fig. 2 (a) $\mathrm{AQP}-1^{+}$cells in the endothelial cell of intrathrombotic neovessels. (b) Changes of intrathrombotic AQP-1 ${ }^{+}$ neovessels numbers after IVC ligation a

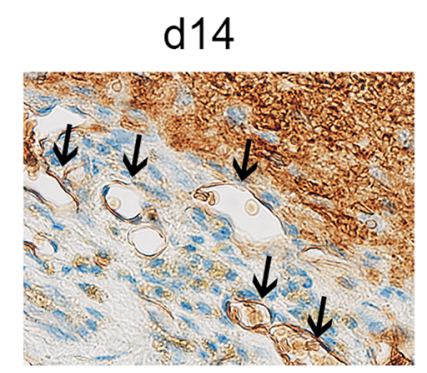

b

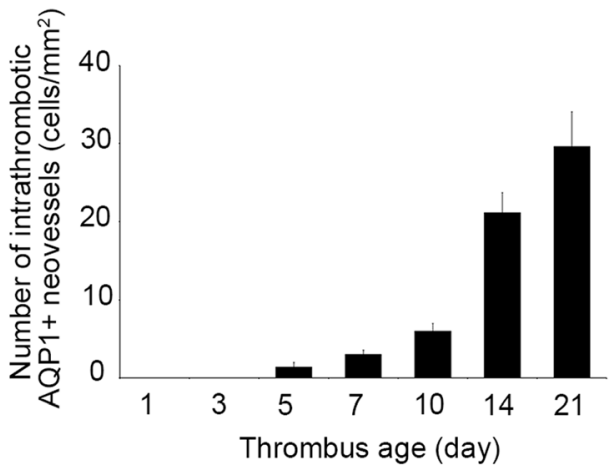

that AQPs might be involved in thrombus formation/resolution. Thus, we tried to examine the expression of AQP-1 and AQP-3 in stasis-induced venous thrombi of mice. Subsequently, we found out the possibility that aquaporins contributed in thrombogenesis/the resolution process.

AQP-1 is widely distributed in various organs, tissues, and cells such as red blood cells, proximal tubular cells, lung, secretory glands, skeletal muscle, and peritoneum except for the central nervous system [32-35]. On the other hand, aquaporin 1 contributes to the coagulation function of the platelet, and the possibility that an aquaporin inhibitor results in anticoagulant action is suggested [36]. The inhibition of AQP-1-dependent water exchange augmented the pressure-induced hemolysis in human erythrocytes, thus indicating that AQP-1 played protective roles in pressureinduced hemolysis [37, 38].

In early phase, thrombus samples were mainly composed of erythrocytes, followed by leukocyte migration. Eventually, thrombus samples were organized by collagen accumulation and neovascularization [39]. In line with these changes, AQP$1^{+}$area on erythrocytes was widely observed and gradually disappeared time dependently. Moreover, AQP-1 was expressed in dermal capillaries [40], indicating that AQP-1 might be associated with angiogenesis but not collagen accumulation [41]. Also, chronic hypertension resulted in the enhancement of AQP-1 expression in vascular endothelium [42]. Actually, we could detect AQP-1+ signals in intrathrombotic neovessels.

AQP-3 is expressed in keratinocytes and epithelial cells of air way and urinary [43-46]. Several lines of accumulating evidence implied that AQP-3 played important roles in tissue repair [39, 47, 48]. AQP-3 promoted keratinocyte migration, and AQP-3-deficient mice showed impaired skin wound healing [39]. Similarly, the lack of AQP-3 in corneal cells retarded corneal reepithelialization [47]. Moreover, AQP-3 was also associated in enterocyte proliferation through glycerol transportation. Thus, the administration of dextran sulfate or acetic acid causes more severe colitis in the absence of AQP-3 [48]. In the present study, we found that intrathrombotic macrophages expressed AQP-3, suggesting that AQP-3 might contribute to macrophage migration. This is supported by the evidence that the function of the macrophage was disturbed in AQP-3 null mice, eventually resulting in a high mortality due to bacterial peritonitis [49]. a
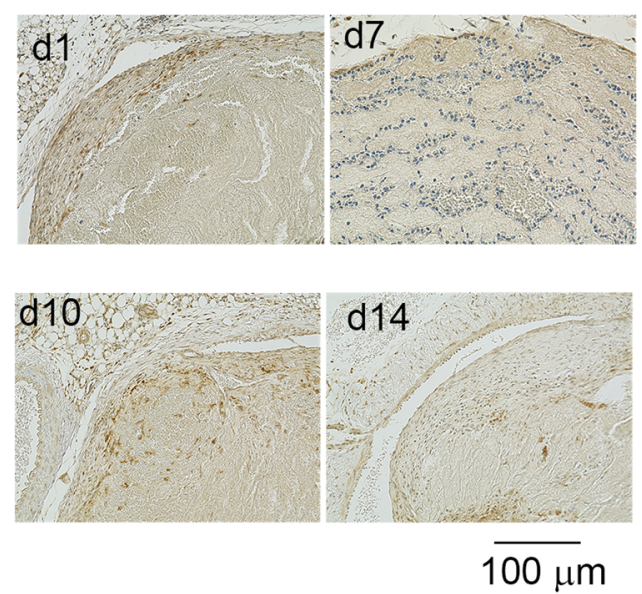

b

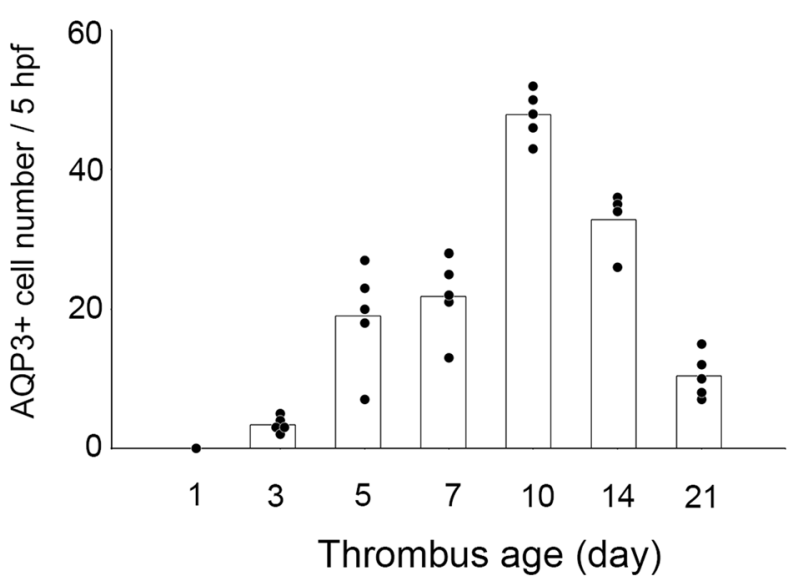

Fig. 3 (a) Immunohistochemical detection of murine intrathrombotic AQP-3 at 1, 7, 10, and 14 days after IVC ligation and (b) changes in intrathrombotic $\mathrm{AQP}-3^{+}$cell numbers after IVC ligation. Original magnification: $\times 400$ 
a

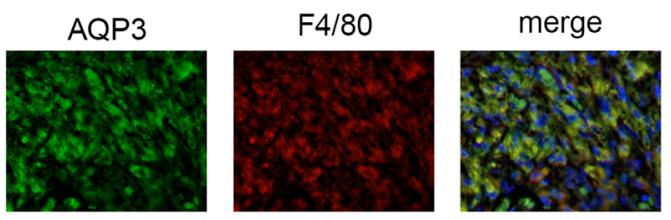

\section{b}

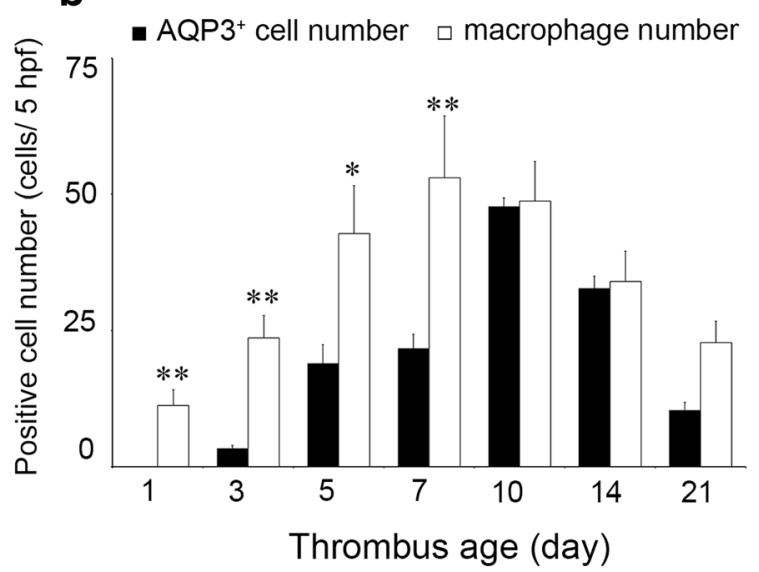

Fig. 4 (a) Double-color immunofluorescence analysis of AQP-3 in intrathrombotic F4/80 macrophages. Fourteen days after IVC ligation; original magnification $\times 400$. (b) Changes in the AQP- $3^{+}$cell number and the $\mathrm{F} 4 / 80^{+}$macrophages numbers

In the present study, we could confirm intrathrombotic expression of AQP-1 and AQP-3, implying that both AQP-1 and AQP-3 were involved in thrombogenesis and resolution. From the aspects of forensic pathology, both AQPs would be available markers for thrombus age estimation. Temporal changes of intrathrombotic AQP-1 expression were mirror image to that of intrathrombotic collagen accumulation. When the intrathrombotic $\mathrm{AQP}-1^{+}$area was as large as the intrathrombotic collagen area or smaller, it would indicate a thrombus age of $\geq 10$ days. AQP $-3^{+}$cell number of $>30$ would indicate a thrombus age of 10-14 days. Moreover, AQP-3 was expressed by a part of intrathrombotic macrophages. The ratio of $\mathrm{AQP}-3^{+}$macrophage number to total macrophage number would be useful for the determination of thrombus ages. Actually, in thrombus samples without intrathrombotic organization, the ratio of $<50 \%$ would indicate a thrombus age of $\leq 7$ days.

Additionally, coronavirus disease 2019 (COVID-19) rapidly spread across the entire globe rapidly. The patients with COVID-19 develop acute lung injury, resulting in the progress to respiratory failure. The initial coagulopathy of COVID19 presents with prominent elevation of D-dimer and fibrin/ fibrinogen degradation products, while abnormalities in

Table 2 Mean intrathrombotic AQP- $3^{+}$cell number and ratio of AQP$3^{+} /$macrophage in each thrombus age group $(n=4-5)$

\begin{tabular}{lcc}
\hline Thrombus age (day) & $\begin{array}{c}\text { AQP-3 } \\
\text { Mean } \pm \text { SEM (range) }\end{array}$ & $\begin{array}{l}\text { AQP-3/macrophage } \\
\text { Mean } \pm \text { SEM (range) }\end{array}$ \\
\hline 1 & $0(-)$ & $0(-)$ \\
3 & $3.40 \pm 0.51(2-5)$ & $0.16 \pm 0.04(0.07-0.29)$ \\
5 & $19.00 \pm 3.36(7-27)$ & $0.50 \pm 0.12(0.15-0.85)$ \\
7 & $21.80 \pm 2.52(13-28)$ & $0.48 \pm 0.07(0.36-0.63)$ \\
10 & $47.80 \pm 1.56(43-52)$ & $1.02 \pm 0.12(0.72-1.43)$ \\
14 & $32.75 \pm 2.29(34-36)$ & $1.03 \pm 0.19(0.76-1.59)$ \\
21 & $10.4 \pm 1.44(7-15)$ & $0.67 \pm 0.28(0.23-1.50)$ \\
\hline
\end{tabular}

prothrombin time, partial thromboplastin time, and platelet counts are relatively uncommon in initial presentations [50, 51]. On the autopsy findings, pulmonary embolism and DVT were observed in the patients with COVID-19 [52-55]. COVID-19 brought down the thrombosis and led to sudden death. In our previous papers on the IVC stasis-induced murine DVT model, we found out the roles of the cytokines, chemokines, and their receptors which developed in neutrophils and macrophages, which constituted a thrombus formation and resolution $[11,12]$. The thrombus age determination would be important in order to clarify the relationship between COVID-19 infection and thrombogenesis using human thrombus samples and to diagnose the cause of death correctly.

Acknowledgments We thank Ms. Mariko Kawaguchi for her excellent assistance in the preparation of this manuscript.

Funding This study was financially supported in part by the Grants-inAid for Scientific Research (A) and (C) from the JSPS.

\section{Compliance with ethical standards}

Conflict of interest The authors declare that they have no conflict of interest.

Ethical approval All procedures performed in studies involving human participants were in accordance with the ethical standards of the Japanese Society for Forensic Pathology.

Informed consent No informed consent was required.

\section{References}

1. Verkman AS (2005) More than just water channels: unexpected cellular roles of aquaporins. J Cell Sci 118:3225-3232. https://doi. org/10.1242/jcs.02519 
2. Zhang JX, Xie CM, Zhu ZW, Huang HY, Zeng ZL (2012) Potential role of AQP-1 and VEGF in the development of malignant pleural effusion in mice. Med Oncol 29:656-662. https://doi.org/10.1007/ s12032-011-9960-6

3. Liu H, Hooper SB, Armugam A, Dawson N, Ferraro T, Jeyaseelan K, Thiel A, Koukoulas I, Wintour EM (2003) Aquaporin gene expression and regulation in the ovine fetal lung. J Physiol 551: 503-514. https://doi.org/10.1113/jphysiol.2003.044875

4. Brown D (2017) The discovery of water channels (aquaporins). Ann Nutr Metab 70(Suppl 1):37-42. https://doi.org/10.1159/ 000463061

5. De Ieso ML, Yool AJ (2018) Mechanisms of aquaporin-facilitated cancer invasion and metastasis. Front Chem 6:135. https://doi.org/ 10.3389 /fchem. 2018.00135

6. Huebert RC, Jagavelu K, Hendrickson HI, Vasdev MM, Arab JP, Splinter PL, Trussoni CE, Larusso NF, Shah VH (2011) Aquaporin-1 promotes angiogenesis, fibrosis, and portal hypertension through mechanisms dependent on osmotically sensitive microRNAs. Am J Pathol 179:1851-1860. https://doi.org/10. 1016/j.ajpath.2011.06.045

7. Stahl K, Rahmani S, Prydz A, Skauli N, MacAulay N, Mylonakou MN, Torp R, Skare Ø, Berg T, Leergaard TB, Paulsen RE, Ottersen OP, Amiry-Moghaddam M (2018) Targeted deletion of the aquaglyceroporin AQP9 is protective in a mouse model of Parkinson's disease. PLoS one 13. DOI: https://doi.org/10.1371/ journal.pone.0194896

8. Hirt L, Fukuda AM, Ambadipudi K, Rashid F, Binder D, Verkman A, Ashwal S, Obenaus A, Badaut J (2017) Improved long-term outcome after transient cerebral ischemia in aquaporin-4 knockout mice. J Cereb Blood Flow Metab 37:277-290. https://doi.org/10. 1177/0271678X15623290

9. Nosaka M, Ishida Y, Kimura A, Kondo T (2010) Immunohistochemical detection of MMP-2 and MMP-9 in a stasis-induced deep vein thrombosis model and its application to thrombus age estimation. Int J Legal Med 124:439-444. https:// doi.org/10.1007/s00414-010-0484-y

10. Nosaka M, Ishida Y, Kuninaka Y, Taruya A, Kimura A, Shimada E, Yamamoto H, Michiue T, Furukawa F, Kondo T, ORCID: http:// orcid.org/0000-0002-5059-8309 (2020) The application of autophagy to thrombus age estimation in murine deep vein thrombosis model. Int J Legal Med 134: 1061-1066. DOI: https://doi.org/10. 1007/s00414-019-02168-0

11. Nosaka M, Ishida Y, Kimura A, Kuninaka Y, Inui M, Mukaida N, Kondo T (2011) Absence of IFN-gamma accelerates thrombus resolution through enhanced MMP-9 and VEGF expression in mice. $\mathrm{J}$ Clin Invest 121:2911-2920. https://doi.org/10.1172/JCI40782

12. Nosaka M, Ishida Y, Kimura A, Kuninaka Y, Taruya A, Furuta M, Mukaida N, Kondo T (2018) Contribution of the TNF-alpha (tumor necrosis factor-alpha)-TNF-Rp55 (tumor necrosis factor receptor p55) axis in the resolution of venous thrombus. Arterioscler Thromb Vasc Biol 38:2638-2650. https://doi.org/10.1161/ ATVBAHA.118.311194

13. Nosaka M, Ishida $Y$, Kimura A, Kuninaka Y, Taruya A, Ozaki M, Tanaka A, Mukaida N, Kondo T (2020) Crucial involvement of IL6 in thrombus resolution in mice via macrophage recruitment and the induction of proteolytic enzymes. Front Immunol 10:3150. https://doi.org/10.3389/fimmu.2019.03150

14. Ishida Y, Kimura A, Takayasu T, Eisenmenger W, Kondo T (2008) Expression of oxygen-regulated protein 150 (ORP150) in skin wound healing and its application for wound age determination. Int J Legal Med 122:409-414

15. Ishida Y, Kimura A, Takayasu T, Eisenmenger W, Kondo T (2009) Detection of fibrocytes in human skin wounds and its application for wound age determination. Int J Legal Med 123:299-304. https:// doi.org/10.1007/s00414-009-0320-4
16. Ishida Y, Kimura A, Nosaka M, Kuninaka Y, Takayasu T, Eisenmenger W, Kondo T (2012) Immunohistochemical analysis on cyclooxygenase-2 for wound age determination. Int J Legal Med 126:435-440. https://doi.org/10.1007/s00414-012-0685-7

17. Ishida Y, Kimura A, Nosaka M, Kuninaka Y, Shimada E, Yamamoto H, Nishiyama K, Inaka S, Takayasu T, Eisenmenger W, Kondo T (2015) Detection of endothelial progenitor cells in human skin wounds and its application for wound age determination. Int J Legal Med 129:1049-1054. https://doi.org/10.1007/ s00414-015-1181-7

18. Ishida Y, Kuninaka Y, Nosaka M, Kimura A, Kawaguchi T, Hama M, Sakamoto S, Shinozaki K, Eisenmenger W, Kondo T (2015) Immunohistochemical analysis on MMP-2 and MMP-9 for wound age determination. Int J Legal Med 129:1043-1048. https://doi.org/ 10.1007/s00414-015-1167-5

19. Kimura A, Ishida Y, Nosaka M, Shiraki M, Hama M, Kawaguchi T, Kuninaka Y, Shimada E, Yamamoto H, Takayasu T, Kondo T (2015) Autophagy in skin wounds: a novel marker for vital reactions. Int J Legal Med 129:537-541. https://doi.org/10.1007/ s00414-015-1168-4

20. Kuninaka $Y$, Ishida $Y$, Nosaka M, Shimada E, Kimura A, Ozaki M, Hata S, Michiue T, Yamamoto H, Furukawa F, Eisenmenger W, Kondo T (2020) Forensic pathological study on temporal appearance of dendritic cells in skin wounds. Int J Legal Med 134:597601. https://doi.org/10.1007/s00414-019-02185-z

21. Ishida Y, Kuninaka Y, Furukawa F, Kimura A, Nosaka M, Fukami M, Yamamoto H, Kato T, Shimada E, Hata S, Takayasu T, Eisenmenger W, Kondo T (2018) Immunohistochemical analysis on aquaporin-1 and aquaporin-3 in skin wounds from the aspects of wound age determination. Int J Legal Med 132:237-242. https:// doi.org/10.1007/s00414-017-1725-0

22. Ishida Y, Kuninaka Y, Nosaka M, Shimada E, Hata S, Yamamoto H, Hashizume Y, Kimura A, Furukawa F, Kondo T (2018) Forensic application of epidermal AQP3 expression to determination of wound vitality in human compressed neck skin. Int J Legal Med 132:1375-1380. https://doi.org/10.1007/s00414-018-1780-1

23. Nosaka M, Ishida Y, Kimura A, Kondo T (2010) Time-dependent organic changes of intravenous thrombi in stasis-induced deep vein thrombosis model and its application to thrombus age determination. Forensic Sci Int 195:143-147. https://doi.org/10.1016/j. forsciint.2009.12.008

24. Kondo T (2007) Timing of skin wounds. Leg Med (Tokyo) 9:109 114. https://doi.org/10.1016/j.legalmed.2006.11.009

25. Cecchi R, Sestili C, Prosperini G, Cecchetto G, Vicini E, Viel G, Muciaccia B (2014) Markers of mechanical asphyxia: immunohistochemical study on autoptic lung tissues. Int J Legal Med 128: 117-125. https://doi.org/10.1007/s00414-013-0876-x

26. Hayashi T, Ishida Y, Mizunuma S, Kimura A, Kondo T (2009) Differential diagnosis between freshwater drowning and saltwater drowning based on intrapulmonary aquaporin-5 expression. Int $\mathrm{J}$ Legal Med 123:7-13. https://doi.org/10.1007/s00414-008-0235-5

27. Wang Q, Ishikawa T, Michiue T, Zhu BL, Guan DW, Maeda $\mathrm{H}$ (2012) Molecular pathology of pulmonary edema after injury in forensic autopsy cases. Int J Legal Med 126:875-882. https://doi. org/10.1007/s00414-012-0758-7

28. Wang Q, Ishikawa T, Michiue T, Zhu BL, Guan DW, Maeda H (2013) Molecular pathology of pulmonary edema in forensic autopsy cases with special regard to fatal hyperthermia and hypothermia. Forensic Sci Int 228:137-141. https://doi.org/10.1016/j.forsciint. 2013.03.007

29. Wang Q, Ishikawa T, Michiue T, Zhu BL, Guan DW, Maeda H (2013) Molecular pathology of brain edema after severe burns in forensic autopsy cases with special regard to the importance of reference gene selection. Int J Legal Med 127:881-889. https:// doi.org/10.1007/s00414-013-0868-x 
30. An JL, Ishida Y, Kimura A, Kondo T (2010) Forensic application of intrarenal aquaporin-2 expression for differential diagnosis between freshwater and saltwater drowning. Int J Legal Med 124:99104. https://doi.org/10.1007/s00414-009-0375-2

31. An JL, Ishida Y, Kimura A, Kondo T (2011) Immunohistochemical examination of intracerebral aquaporin-4 expression and its application for differential diagnosis between freshwater and saltwater drowning. Int J Legal Med 125:59-65. https://doi.org/10.1007/ s00414-010-0523-8

32. Nielsen S, Smith BL, Christensen EI, Agre P (1993) Distribution of the aquaporin CHIP in secretory and resorptive epithelia and capillary endothelia. Proc Natl Acad Sci U S A 90:7275-7279. https:// doi.org/10.1073/pnas.90.15.7275

33. Hasegawa H, Lian SC, Finkbeiner WE, Verkman AS (1994) Extrarenal tissue distribution of CHIP28 water channels by in situ hybridization and antibody staining. Am J Phys 266:C893-C903. https://doi.org/10.1152/ajpcell.1994.266.4.C893

34. Verkman AS (2006) Aquaporins in endothelia. Kidney Int 69: 1120-1123. https://doi.org/10.1038/sj.ki.5000226

35. Dolman D, Drndarski S, Abbott NJ, Rattray M (2005) Induction of aquaporin 1 but not aquaporin 4 messenger RNA in rat primary brain microvessel endothelial cells in culture. J Neurochem 93: 825-833. https://doi.org/10.1111/j.1471-4159.2005.03111.x

36. Agbani EO, Williams CM, Li Y, van den Bosch MT, Moore SF, Mauroux A, Hodgson L, Verkman AS, Hers I, Poole AW (2018) Aquaporin-1 regulates platelet procoagulant membrane dynamics and in vivo thrombosis. JCI Insight 3. https://doi.org/10.1172/jci. insight.99062

37. Yamaguchi T, Iwata Y, Miura S, Maehara Y, Nozawa K (2012) Enhancement of pressure-induced hemolysis by aquaporin-1 inhibitors in human erythrocytes. Bull Chem Soc Jpn 85:497-503

38. Yamaguchi T, Miyauchi S, Isahara (2103) Pressure-induced hemolysis of in vivo aged human erythrocytes is enhanced by inhibition of water transport via aquaporin-1. High Press Res 33: 285-291

39. Hara-Chikuma M, Verkman AS (2008) Aquaporin-3 facilitates epidermal cell migration and proliferation during wound healing. J Mol Med (Berl) 86:221-231. https://doi.org/10.1007/s00109-0070272-4

40. Agren J, Zelenin S, Håkansson M, Eklöf AC, Aperia A, Nejsum LN, Nielsen S, Sedin G (2003) Transepidermal water loss in developing rats: role of aquaporins in the immature skin. Pediatr Res 53: 558-565. https://doi.org/10.1203/01.PDR.0000055777.25933.98

41. Saadoun S, Papadopoulos MC, Hara-Chikuma M, Verkman AS (2005) Impairment of angiogenesis and cell migration by targeted aquaporin-1 gene disruption. Nature 434:786-792. https://doi.org/ 10.1038 /nature 03460

42. Toussaint J, Raval CB, Nguyen T, Fadaifard H, Joshi S, Wolberg G, Quarfordt S, Jan KM, Rumschitzki DS (2017) Chronic hypertension increases aortic endothelial hydraulic conductivity by upregulating endothelial aquaporin-1 expression. Am J Physiol Heart Circ Physiol 313:H1063-H1073. https://doi.org/10.1152/ajpheart. 00651.2016

43. Frigeri A, Gropper MA, Umenishi F, Kawashima M, Brown D, Verkman AS (1995) Localization of MIWC and GLIP water channel homologs in neuromuscular, epithelial and glandular tissues. J Cell Sci 108:2993-3002

44. Echevarria M, Windhager EE, Tate SS, Frindt G (1994) Cloning and expression of AQP3, a water channel from the medullary collecting duct of rat kidney. Proc Natl Acad Sci U S A 91: 10997-11001. https://doi.org/10.1073/pnas.91.23.10997

45. Ishibashi K, Sasaki S, Fushimi K, Uchida S, Kuwahara M, Saito H, Furukawa T, Nakajima K, Yamaguchi Y, Gojobori T et al (1994) Molecular cloning and expression of a member of the aquaporin family with permeability to glycerol and urea in addition to water expressed at the basolateral membrane of kidney collecting duct cells. Proc Natl Acad Sci U S A 91:6269-6273. https://doi.org/10. 1073/pnas.91.14.6269

46. Ma T, Frigeri A, Hasegawa H, Verkman AS (1994) Cloning of a water channel homolog expressed in brain meningeal cells and kidney collecting duct that functions as a stilbene-sensitive glycerol transporter. J Biol Chem 269:21845-21849

47. Levin MH, Verkman AS (2006) Aquaporin-3-dependent cell migration and proliferation during corneal re-epithelialization. Invest Ophthalmol Vis Sci 47:4365-4372. https://doi.org/10.1167/iovs. 06-0335

48. Thiagarajah JR, Zhao D, Verkman AS (2007) Impaired enterocyte proliferation in aquaporin-3 deficiency in mouse models of colitis. Gut 56:1529-1535. https://doi.org/10.1136/gut.2006.104620

49. Zhu N, Feng X, He C, Gao H, Yang L, Ma Q, Guo L, Qiao Y, Yang $\mathrm{H}$, Ma T (2011) Defective macrophage function in aquaporin-3 deficiency. FASEB J 25:4233-4239. https://doi.org/10.1096/fj.11182808

50. Connors JM, Levy JH (2020) COVID-19 and its implications for thrombosis and anticoagulation. Blood 135:2033-2040. https://doi. org/10.1182/blood.2020006000

51. Bikdeli B, Madhavan MV, Jimenez D, Chuich T, Dreyfus I, Driggin E, Nigoghossian C, Ageno W, Madjid M, Guo Y, Tang LV, Hu Y, Giri J, Cushman M, Quéré I, Dimakakos EP, Gibson CM, Lippi G, Favaloro EJ, Fareed J, Caprini JA, Tafur AJ, Burton JR, Francese DP, Wang EY, Falanga A, McLintock C, Hunt BJ, Spyropoulos AC, Barnes GD, Eikelboom JW, Weinberg I, Schulman S, Carrier M, Piazza G, Beckman JA, Steg PG, Stone GW, Rosenkranz S, Goldhaber SZ, Parikh SA, Monreal M, Krumholz HM, Konstantinides SV, Weitz JI, Lip GYH (2020) COVID-19 and thrombotic or thromboembolic disease: implications for prevention, antithrombotic therapy, and follow-up: JACC state-of-the-art review. J Am Coll Cardiol 75:2950-2973. https://doi.org/10.1016/j.jacc.2020.04.031

52. Wichmann D, Sperhake JP, Lütgehetmann M, Steurer S, Edler C, Heinemann A, Heinrich F, Mushumba H, Kniep I, Schröder AS, Burdelski C, de Heer G, Nierhaus A, Frings D, Pfefferle S, Becker $\mathrm{H}$, Bredereke-Wiedling $\mathrm{H}$, de Weerth A, Paschen HR, Sheikhzadeh-Eggers S, Stang A, Schmiedel S, Bokemeyer C, Addo MM, Aepfelbacher M, Püschel K, Kluge S (2020) Autopsy findings and venous thromboembolism in patients with COVID-19. Ann Intern Med 173:M20-M2003. https://doi.org/10.7326/M202003

53. Ackermann M, Verleden SE, Kuehnel M, Haverich A, Welte T, Laenger F, Vanstapel A, Werlein C, Stark H, Tzankov A, Li WW, Li VW, Mentzer SJ, Jonigk D (2020) Pulmonary vascular endothelialitis, thrombosis, and angiogenesis in Covid-19. N Engl J Med 383:120-128. https://doi.org/10.1056/NEJMoa2015432

54. Fox SE, Akmatbekov A, Harbert JL, Li G, Quincy Brown J, Vander Heide RS (2020) Pulmonary and cardiac pathology in African American patients with COVID-19: an autopsy series from New Orleans. Lancet Respir Med 8(7):681-686. https://doi.org/10.1016/ S2213-2600(20)30243-5

55. Edler C, Schröder AS, Aepfelbacher M, Fitzek A, Heinemann A, Heinrich F, Klein A, Langenwalder F, Lütgehetmann M, Meier K, Püschel K, Schädler J, Steurer S, Mushumba H, Sperhake JP (2020) Dying with SARS-CoV-2 infection-an autopsy study of the first consecutive 80 cases in Hamburg, Germany. Int J Legal Med 134:1275-1284. https://doi.org/10.1007/s00414-020-02317-w

Publisher's note Springer Nature remains neutral with regard to jurisdictional claims in published maps and institutional affiliations. 